Pacific Journal of Mathematics

PSEUDOCONVEX DOMAINS WITH PEAK FUNCTIONS AT 


\title{
PSEUDOCONVEX DOMAINS WITH PEAK FUNCTIONS AT EACH POINT OF THE BOUNDARY
}

\author{
ANDREI IORDAN
}

\begin{abstract}
Under certain conditions, each point of the boundary of a smoothly bounded weakly pseudoconvex domain $D$ in $C^{n}$ is a peak point of $A^{\infty}(D)$.
\end{abstract}

1. Introduction. Let $D$ be a bounded pseudoconvex domain with $C^{\infty}$ boundary. We denote by $A^{\infty}(D)$ the set of holomorphic functions in $D$ which have a $C^{\infty}$ extension to $\bar{D}$. A compact subset $E$ of $\partial D$ is a peak set for $A^{\infty}(D)$ if there exists $f \in A^{\infty}(D)$ such that $f=0$ on $E$ and $\operatorname{Re} f>0$ on $\bar{D} \backslash E$. Such a function will be called a strong support function for $E$. If $E=\{p\}, p$ is a peak point for $A^{\infty}(D)$.

In [6], [18] it is proved that each point of a strictly pseudoconvex domain is a peak point for $A^{\infty}(D)$ with a strong support function holomorphic in the neighborhood of $\bar{D}$ and in [7], [17] it is proved that each strongly pseudoconvex point of a weakly pseudoconvex domain with $C^{\infty}$ boundary is a peak point for $A^{\infty}(D)$. These results fail in the case of weakly pseudoconvex domains [4], [13]. Other results about smoothly varying peaking functions in pseudoconvex domains may be found in [1], [5], [14].

If $D$ is strictly pseudoconvex, Chaumat and Chollet proved in [3] that each closed subset of a peak set for $A^{\infty}(D)$ is a peak set for $A^{\infty}(D)$. The assertion is also true for bounded pseudoconvex domains in $\mathbf{C}^{2}$ of finite type [15] and for bounded pseudoconvex domains in $\mathrm{C}^{2}$ with isolated degeneracies [11] or with (NP) property [12].

In [16] is given an example of convex domain in $\mathbf{C}^{2}$ not of finite type whose weakly pseudoconvex boundary points form a line segment which is a peak set for $A^{\infty}(D)$, but there is a point which is not a peak point for $A^{\infty}(D)$.

Here we prove that, under certain assumptions, each point of the boundary of a weakly pseudoconvex domain is a peak point for $A^{\infty}(D)$.

Some results of this paper were announced at the International Workshop Geometric and Quantitative Complex Analysis, Wuppertal 1986. 
This paper was started while the author held a position of research mathematician at Tel-Aviv University. The author wishes to thank the Mathematics Department for the conditions of work created.

\section{A Morse lemma for non-negative strictly $q$-pseudoconvex func- tions.}

LEMMA 1. Let $\varphi$ be a real-valued non-negative function defined in a neighborhood of $0 \in \mathbf{C}^{n}$ such that $\varphi(0)=0$. We suppose that the complex Hessian of $\varphi$ at 0 has $q$ zero eigenvalues at the origin. Then there exists a complex-linear change of coordinates in $\mathbf{C}^{n}$ such that

$$
\varphi(z)=\sum_{j=1}^{r}\left(1+\lambda_{j}\right) x_{j}^{2}+\sum_{j=1}^{r}\left(1-\lambda_{j}\right) y_{j}^{2}+O\left(|z|^{3}\right)
$$

where $1 \geq \lambda_{j} \geq 0, z=x+i y, r=n-q$.

REMARK 1. Lemma 1 is a more complete form of Lemma 4 of [10]. For strictly plurisubharmonic functions the result was obtained in [9].

Proof of Lemma 1. The proof is similar to the proof of Lemma 4 of [10] and most of it is presented there. The point 0 is a local minimum for $\varphi$ so $\operatorname{grad} \varphi(0)=0$ and the real Hessian of $\varphi$ at 0 is semi-positive definite. By [18] it follows that the complex Hessian of $\varphi$ is semi-positive definite at 0 . We denote

$$
\begin{aligned}
& x^{\prime}=\left(x_{1}, \ldots, x_{r}\right), \quad x^{\prime \prime}=\left(x_{r+1}, \ldots, x_{n}\right), \quad y^{\prime}=\left(y_{1}, \ldots, y_{r}\right), \\
& y^{\prime \prime}=\left(y_{r+1}, \ldots, y_{n}\right), \quad z^{\prime}=x^{\prime}+i y^{\prime}, \quad z^{\prime \prime}=x^{\prime \prime}+i y^{\prime \prime} .
\end{aligned}
$$

We have

$$
\begin{aligned}
\varphi(z)= & \operatorname{Re} \sum_{i, j=1}^{n} \frac{\partial^{2} \varphi}{\partial z_{i} \partial z_{j}}(0) z_{i} z_{j} \\
& +\sum_{i, j=1}^{n} \frac{\partial^{2} \varphi}{\partial z_{i} \partial \bar{z}_{j}}(0) z_{i} \bar{z}_{j}+O\left(|z|^{3}\right) .
\end{aligned}
$$

By making a complex-linear change of coordinates in $\mathbf{C}^{n}$ we may suppose that

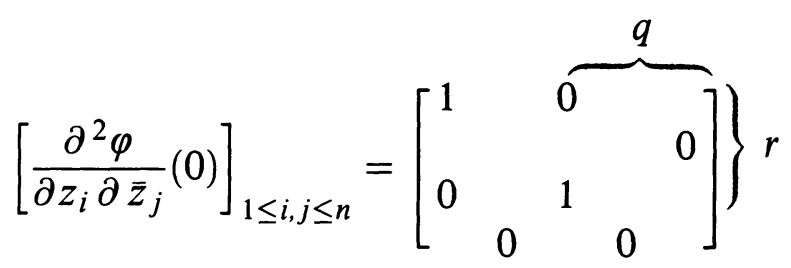


and $\varphi(z)=\left|z^{\prime}\right|^{2}+\operatorname{Re}\left({ }^{t} z S z\right)+O\left(|z|^{3}\right)$ where

$$
S=\left[\frac{\partial^{2} \varphi}{\partial z_{i} \partial z_{j}}(0)\right]_{1 \leq i, j \leq n}
$$

Let $s=\left[\left(\begin{array}{l}x \\ y\end{array}\right)\right]$ be a real $2 n$-vector in $\mathbf{R}^{2 n}$, where $x, y \in \mathbf{R}^{n}$,

$$
E^{\prime}=\left\{s \in \mathbf{R}^{2 n} \mid x^{\prime \prime}=0, y^{\prime \prime}=0\right\}, \quad E^{\prime \prime}=\left\{s \in \mathbf{R}^{2 n} \mid x^{\prime}=0, y^{\prime}=0\right\} .
$$

We shall identify $E^{\prime}$ with $\mathbf{R}^{2 r}$ and $E^{\prime \prime}$ with $\mathbf{R}^{2(n-r)} . E^{\prime}$ and $E^{\prime \prime}$ are complex subspaces of $\mathbf{C}^{n}=E^{\prime} \oplus E^{\prime \prime}$ and for $s \in \mathrm{C}^{n}$ we obtain $s=s^{\prime}+s^{\prime \prime}$ with $s^{\prime} \in E^{\prime}, s^{\prime \prime} \in E^{\prime \prime}$. With these notations we obtain that

$$
\varphi(s)=\left|s^{\prime}\right|^{2}+{ }^{t} s T s+O\left(|s|^{3}\right)=\left|s^{\prime}\right|^{2}+\langle T s, s\rangle+O\left(|s|^{3}\right)
$$

where $\langle$,$\rangle is the inner product in \mathbf{R}^{2 n}$ and $T=\left[\begin{array}{cc}A & -B \\ -B & -A\end{array}\right]$ with $S=$ $A+i B, A$ and $B$ real symmetric matrices. In [10] we prove that

$$
\langle T s, s\rangle=\left\langle T_{1}^{\prime} s^{\prime}, s^{\prime}\right\rangle+\left\langle T_{2}^{\prime} s^{\prime}, s^{\prime \prime}\right\rangle+\left\langle T_{1}^{\prime \prime} s^{\prime \prime}, s^{\prime}\right\rangle+\left\langle T_{2}^{\prime \prime} s^{\prime \prime}, s^{\prime \prime}\right\rangle
$$

where

$$
T_{1}^{\prime}=\left[\begin{array}{cccc}
A_{1}^{\prime} & 0 & -B_{1}^{\prime} & 0 \\
0 & 0 & 0 & 0 \\
-B_{1}^{\prime} & 0 & -A_{1}^{\prime} & 0 \\
0 & 0 & 0 & 0
\end{array}\right], \quad T_{2}^{\prime \prime}=\left[\begin{array}{cccc}
0 & 0 & 0 & 0 \\
0 & A_{2}^{\prime \prime} & 0 & -B_{2}^{\prime \prime} \\
0 & 0 & 0 & 0 \\
0 & -B_{2}^{\prime \prime} & 0 & -A_{2}^{\prime \prime}
\end{array}\right]
$$

and $A_{2}^{\prime \prime}, B_{2}^{\prime \prime}$ are the $r \times r(n-r \times n-r)$ matrices obtained by taking the first $r$ (the last $n-r$ ) rows and columns of $A$ and $B$ respectively.

Let $J$ be the real orthogonal matrix representing the multiplication by $i=\sqrt{-1}$, i.e., $J\left[\left(\begin{array}{l}x \\ y\end{array}\right)\right]=\left[\left(\begin{array}{c}-y \\ x\end{array}\right)\right]$. If $v^{\prime} \in E\left(v^{\prime \prime} \in E^{\prime \prime}\right)$ is an eigenvector for $T_{1}^{\prime}\left(T_{2}^{\prime \prime}\right)$ with eigenvalue $\lambda$, then $J v^{\prime}\left(J v^{\prime \prime}\right)$ is an eigenvector for $T_{1}^{\prime}$ $\left(T_{2}^{\prime \prime}\right)$ with eigenvalue $-\lambda$. Because $A$ and $B$ are symmetric matrices, it follows that $T_{1}^{\prime}, T_{2}^{\prime \prime}$ are symmetric matrices. We may therefore consider an orthonormal basis of $\mathbf{R}^{2 n}$ by the form $v_{1}^{\prime}, \ldots, v_{r}^{\prime}, v_{r+1}^{\prime \prime}, \ldots, v_{n}^{\prime \prime}$, $J v_{1}^{\prime}, \ldots, J v_{r}^{\prime}, J v_{r+1}^{\prime \prime}, \ldots, J v_{n}^{\prime \prime}$, where $v_{j}^{\prime}, J v_{j}^{\prime}, v_{j}^{\prime \prime}, J v_{j}^{\prime \prime}$, are eigenvectors for $T_{1}^{\prime}$, respectively $T_{2}^{\prime \prime}$. If $\lambda_{j}$ is the eigenvalue of $v_{j}^{\prime}\left(v_{j}^{\prime \prime}\right)$, by interchanging $v_{j}$ and $J v_{j}$ if necessary we may assume each $\lambda_{j} \geq 0$. 
We have in fact a complex-linear change of coordinates in $\mathbf{C}^{n}$ and if the new coordinates are denoted also by $\left(z_{1}, \ldots, z_{n}\right)$, we have

$$
\begin{aligned}
\varphi(z)= & \sum_{j=1}^{r}\left(1+\lambda_{j}\right) x_{j}^{2}+\sum_{j=1}^{r}\left(1-\lambda_{j}\right) y_{j}^{2} \\
& +\sum_{i=1}^{r} \sum_{j=r+1}^{n}\left(a_{i j} x_{i} x_{j}+b_{i j} x_{i} y_{j}+c_{i j} x_{j} y_{i}+d_{i j} y_{i} y_{j}\right) \\
& +\sum_{j=r+1}^{n} \lambda_{j} x_{j}^{2}-\sum_{j=r+1}^{n} \lambda_{j} y_{j}^{2}+O\left(|z|^{3}\right) .
\end{aligned}
$$

Because the real Hessian of $\varphi$ at 0 is semi-positive definite, it follows that $\lambda_{j} \leq 1$ for $j=1, \ldots, r$ and $\lambda_{j}=0$ for $j=r+1, \ldots, n$. If for some $1 \leq i \leq r$ we have $\lambda_{i}=1$, then $c_{i j}=d_{i j}=0$ for $j=r+1, \ldots, n$, because $c_{i j} x_{j} y_{i}$ and $d_{i j} y_{i} y_{j}$ change sign at the origin if $c_{i j} \neq 0, d_{i j} \neq 0$. Thus

$$
\begin{aligned}
\varphi(z) & \left.=\sum_{i=1}^{r}\left[\sqrt{\left(1+\lambda_{i}\right.}\right) x_{i}+\sum_{j=r+1}^{n} \frac{a_{i j}}{2 \sqrt{1+\lambda_{i}}} x_{j}+\sum_{j=r+1}^{n} \frac{b_{i j}}{2 \sqrt{1+\lambda_{i}}} y_{j}\right]^{2} \\
& +\sum_{i=1}^{r}\left[\sqrt{\left(1-\lambda_{i}\right)} y_{i}+\sum_{j=r+1}^{n} \frac{c_{i j}}{2 \sqrt{1-\lambda_{i}}} x_{j}+\sum_{j=r+1}^{n} \frac{d_{i j}}{2 \sqrt{1-\lambda_{i}}} y_{j}\right]^{2} \\
& -\frac{1}{4} \sum_{i=1}^{r} \frac{1}{1+\lambda_{i}}\left[\sum_{j=r+1}^{n}\left(a_{i j}^{2} x_{j}^{2}+b_{i j}^{2} y_{j}^{2}\right)\right. \\
& \left.+\sum_{j, k=r+1}^{n}\left(a_{i j} a_{i k} x_{j} x_{k}+b_{i j} b_{i k} y_{j} y_{k}+2 a_{i k} b_{i k} x_{j} y_{k}\right)\right] \\
& -\frac{1}{4} \sum_{i=1}^{r} \frac{1}{1-\lambda_{i}}\left[\sum_{j=r+1}^{n}\left(c_{i j}^{2} x_{j}^{2}+d_{i j}^{2} y_{j}^{2}\right)\right. \\
+ & \left.+\sum_{j, k=r+1}^{n}\left(c_{i j} c_{i k} x_{j} x_{k}+d_{i j} d_{i k} y_{j} y_{k}+2 c_{i j} d_{i k} x_{j} y_{k}\right)\right]
\end{aligned}
$$

where $\Sigma^{\prime}$ means that we take the sum over the indices $i$ for which $\lambda_{i}<1$. Because $\varphi \geq 0$ in the neighborhood of the origin, we obtain that $a_{i j}=b_{i j}=c_{i j}=d_{i j}=0$ for each $i=1, \ldots, r, j=r+1, \ldots, n$. 


\section{Local properties of strong support functions.}

LeMmA 2. Let $D \subset \mathbf{C}^{n}$ be a pseudoconvex domain with smooth boundary, $E \subset \partial D$ a peak set for $A^{\infty}(D), f$ a strong support function for $E$ and $p \in E$. Let $\rho$ be a local defining function for $\partial D$ in the neighborhood of $p$. We denote $C_{p}(\rho, f)=-(\partial \operatorname{Re} f / \partial n)(p) \rho+\operatorname{Re} f$, where $\partial / \partial n$ is the derivative with respect to the normal direction at $p$. Then:

(a) $H^{r} C_{p}(\rho, f)(p)$ is semi-positive definite, where $H^{r}$ represents the real Hessian restricted to the complex-tangent space $T C_{p}(\partial D)$;

(b) $H^{c} C_{p}(\rho, f)(p)=-(\partial \operatorname{Re} f / \partial n)(p) L_{p}$ where $H^{c}$ is the complex Hessian restricted to $T C_{p}(\partial D)$ and $L_{p}$ is the Levi form at $p$;

(c) Suppose that $L_{p}$ has $q$ zero-eigenvalues and $r=n-q-1$ strictly positive eigenvalues at $p$. Let $e_{1}, \ldots, e_{r}$ be the eigenvectors corresponding to the strictly positive eigenvalues and $V_{p}^{\prime}$ the real subspace generated by $e_{1}, \ldots, e_{r}$. If $V_{p}^{+}$is the subspace of $T C_{p}(\partial D)$ generated by the eigenvectors corresponding to the strictly positive eigenvalues of $H^{r} C_{p}(\rho, f)(p)$, then $V_{p}^{\prime} \subset V_{p}^{+}$.

REMARK 2. By the Hopf lemma we have $(\partial \operatorname{Re} f / \partial n)(p)>0$.

Proof. The proof of Lemma 2 is similar to the proof of Proposition 9 of [3] and we shall repeat the arguments from the beginning of it.

By making a complex-linear change of coordinates in $\mathbf{C}^{n}$ we may suppose that $p$ is the origin and in the neighborhood $U_{1}$ of the origin $D$ is given by $D \cap U_{1}=\left\{\left(z^{\prime}, w\right) \in U_{1} \mid \rho\left(z^{\prime}, w\right)<0\right\}$ where $z^{\prime}=$ $\left(z_{1}, \ldots, z_{n-1}\right), z_{j}=x_{j}+i y_{j}, w=u+i v$ and $\rho\left(z^{\prime}, w\right)=u+R_{1}(z)+$ $R_{2}\left(z^{\prime}, w\right)$, where $R_{1}\left(z^{\prime}\right)$ is a second order homogeneous polynomial in $z^{\prime}, \bar{z}^{\prime}$, and $R_{2}\left(z^{\prime}, w\right)=O\left(\left|z^{\prime}\right||w|+|w|^{2}+\left|z^{\prime}\right|^{3}\right)$.

Because $(0,0)$ is a local minimum for $\operatorname{Re} f$, by the Hopf lemma we obtain that

$$
\begin{gathered}
\frac{\partial \operatorname{Re} f}{\partial u}(0,0)<0, \quad \frac{\partial \operatorname{Re} f}{\partial v}(0,0)=0, \\
\frac{\partial \operatorname{Re} f}{\partial x_{j}}(0,0)=\frac{\partial \operatorname{Re} f}{\partial y_{j}}(0,0)=0, \quad 1 \leq j \leq n-1 .
\end{gathered}
$$

It follows that in a neighborhood $U_{2}$ of the origin, $U_{2} \subset U_{1}$, we have

$$
\operatorname{Re} f\left(z^{\prime}, w\right)=\frac{\partial \operatorname{Re} f}{\partial u}(0,0) u+K_{1}\left(z^{\prime}, w\right)+K_{2}\left(z^{\prime}, w\right)
$$


where $K_{1}\left(z^{\prime}, w\right)$ is a second order pluriharmonic polynomial in $z^{\prime}, \bar{z}$, $w, \bar{w}$ and $K_{2}\left(z^{\prime}, w\right)=O\left(\left(\left|z^{\prime}\right|+|w|\right)^{3}\right)$.

From the Cauchy-Riemann equations at the origin we obtain that

$$
\begin{gathered}
\frac{\partial \operatorname{Im} f}{\partial v}(0,0)<0, \quad \frac{\partial \operatorname{Im} f}{\partial u}(0,0)=0, \\
\frac{\partial \operatorname{Im} f}{\partial x_{j}}(0,0)=\frac{\partial \operatorname{Im} f}{\partial y_{j}}(0,0)=0, \quad j=1, \ldots, n-1 .
\end{gathered}
$$

Because

$$
\frac{\partial(\rho, \operatorname{Im} f)}{\partial(w, \bar{w})}(0,0)=\frac{i}{2} \frac{\partial \operatorname{Re} f}{\partial u}(0,0) \neq 0
$$

it follows that the set $\Sigma=\left\{\left(z^{\prime}, w\right) \mid \rho\left(z^{\prime}, w\right)=0, \operatorname{Im} f\left(z^{\prime}, w\right)=0\right\}$ is in a neighborhood $U_{3}$ of the origin, $U_{3} \subset U_{2}$, a $2 n$-2-dimensional $C^{\infty}$-submanifold of the boundary which contains $E \cap U_{3}$.

So, there exists a $C^{\infty}$-function $h=h\left(z^{\prime}\right)$ defined in a neighborhood $V_{1}$ of $0 \in C^{n-1}$ such that $\Sigma=\left\{\left(z^{\prime}, w\right) \mid w=h\left(z^{\prime}\right)\right\}$.

We have $\rho\left(z^{\prime}, h\left(z^{\prime}\right)\right)=0=\operatorname{Re} h\left(z^{\prime}\right)+R_{1}\left(z^{\prime}\right)+R_{2}\left(z^{\prime}, h\left(z^{\prime}\right)\right)$ and because the first order derivatives of $h$ vanish at the origin we obtain that $\operatorname{Re} h\left(z^{\prime}\right)=-R_{1}\left(z^{\prime}\right)+O\left(\left|z^{\prime}\right|^{3}\right)$.

We define

$$
\begin{aligned}
\Theta\left(z^{\prime}\right) & =\operatorname{Re} f\left(z^{\prime}, h\left(z^{\prime}\right)\right) \\
& =\frac{\partial \operatorname{Re} f}{\partial u}(0,0) \operatorname{Re} h\left(z^{\prime}\right)+K_{1}\left(z^{\prime}, h\left(z^{\prime}\right)\right)+K_{2}\left(z^{\prime}, h\left(z^{\prime}\right)\right) \\
& =-\frac{\partial \operatorname{Re} f}{\partial u}(0,0) R_{1}\left(z^{\prime}\right)+K_{1}\left(z^{\prime}, 0\right)+O\left(\left|z^{\prime}\right|^{3}\right),
\end{aligned}
$$

and we obtain (b).

The complex tangent space of $\partial D$ at $(0,0)$ is $\left\{\left(z^{\prime}, w\right) \mid w=0\right\}$, hence the complex Hessian of $\Theta$ has $n-q-1$ strictly positive eigenvalues and $q$ zero-eigenvalues at 0 .

Because $f$ is a strong support function for $E$ we have $\Theta\left(z^{\prime}\right) \geq 0$ and $\Theta\left(z^{\prime}\right)=0$ if and only if $\left(z^{\prime}, h\left(z^{\prime}\right)\right) \in E$. Because the origin is a minimum for $\Theta$, we obtain (a).

We denote by $Z=\left\{z \in V_{1} \mid \Theta\left(z^{\prime}\right)=0\right\}$.

From Lemma 1 it follows that there exists a complex-linear change of coordinates in $\mathbf{C}^{n-1}$ such that in the new coordinates (which we shall denote also $\left.z^{\prime}=\left(z_{1}, \ldots, z_{n-1}\right)\right)$ we have:

(1) $\Theta\left(z^{\prime}\right)=\sum_{j=1}^{n-q-1}\left(1-\lambda_{j}\right) x_{j}^{2}+\sum_{j=1}^{n-q-1}\left(1-\lambda_{j}\right) y_{j}^{2}+O\left(|z|^{3}\right), \quad \lambda_{j} \geq 0$,

and we obtain (c). 
Proposition 1. Let $D \subset \mathbf{C}^{n}$ be a pseudoconvex domain with smooth boundary, $E \subset \partial D$ a peak set for $A^{\infty}(D), f$ a strong support function for $E$ and $p \in E$ such that the Levi form has $q$ zero-eigenvalues at p. We denote by $Z_{p}$ the complex q-dimensional subspace of $T C_{p}(\partial D)$ generated by the eigenvectors corresponding to the zero-eigenvalues.

Using the notations of Lemma 2, suppose that:

(i) $H^{r} C_{p}(\rho, f)(p)$ has at least $n-1$ strictly positive eigenvalues;

(ii) There exists a neighborhood $V$ of $p$ and $a q+1$ codimensional generic submanifold $S$ of $\partial D$ such that $E \cap V \subset S$ and $T C_{p}(S) \oplus Z_{p}=$ $T C_{p}(\partial D)$;

(iii) The tangent space $T_{p}(S)$ has a $q$ dimensional complement $V_{p}$ in $T_{p}(\partial D)$ which is contained in $W_{p}$, where $V_{p}^{\prime} \oplus W_{p}=V_{p}^{+}$.

Then there exists a neighborhood $\omega$ of $p$, an n-dimensional totally real submanifold of $\partial D \cap \omega$ and $c>0$ such that $E \cap \omega \subset M$ and $\operatorname{Re} f(z) \geq c d(z, M)^{2}$ for each $z \in \bar{D} \cap \omega$.

REMARK 3. The conditions (ii) and (iii) mean that there exist $\rho_{1}, \ldots$, $\rho_{q}$ defined in the neighborhood of $p$ such that

$$
\frac{\partial\left(\rho_{1}, \ldots, \rho_{q}\right)}{\partial\left(z_{1}, \ldots, z_{q}\right)}(p) \text { and } \frac{\partial\left(\rho_{1}, \ldots, \rho_{q}\right)}{\partial\left(y_{1}^{\prime}, \ldots, y_{q}^{\prime}\right)}(p)
$$

have maximal rank, where $z_{1}, \ldots, z_{q}$, respectively $y_{1}^{\prime}, \ldots, y_{q}^{\prime}$ are the variables corresponding to $Z_{p}$, respectively to $V_{p}$.

Proof. We shall use the notations from the proof of Lemma 2 and continue the proof with the methods used in the proof of Proposition 9 of [3] and Proposition 3 of [11].

The set

$$
N=\left\{z^{\prime} \in V_{1} \mid \frac{\partial \Theta}{\partial x_{j}}\left(z^{\prime}\right)=0,1 \leq j \leq n-q-1\right\}
$$

is in a neighborhood $V_{2} \subset V_{1}$ of $0 \in \mathrm{C}^{n-1}$ an $n+q-1$-dimensional generic submanifold of $C^{n-1}$ which contains $Z \cap V_{2}$.

We denote by $\tau(z)=J(\operatorname{grad} \rho(z))$ where $J$ represents the complex structure on $\mathbf{C}^{n}=\mathbf{R}^{2 n}$. Because $T_{0}(\Sigma)=\{(z, w) \mid w=0\}$, it follows that $\tau$ is transversal to $\Sigma$ at $(0,0)$, hence there exists a neighborhood $U_{4} \subset U_{3}$ such that $\tau$ is transversal to $\Sigma$ on $U_{4}$.

Therefore there exists a $\mathbf{C}^{\infty}$-diffeomorphism $\varphi$ defined on

$$
0_{\varepsilon}=\left\{\left(z^{\prime}, t\right) \mid z^{\prime} \in V_{2}, t \in(-\varepsilon, \varepsilon)\right\}
$$


with values in $\partial D$ such that

$$
\varphi\left(z^{\prime}, 0\right)=\left(z^{\prime}, h\left(z^{\prime}\right)\right) \text { and } \frac{\partial \varphi}{\partial t}\left(z^{\prime}, 0\right)=\tau\left(z^{\prime}, h\left(z^{\prime}\right)\right) .
$$

Because $Z \cap V_{2} \subset N$ we have

$$
E \cap U_{4} \subset \varphi(Z \times\{0\}) \subset \varphi(N \times\{0\}) .
$$

We denote by $\Phi\left(z^{\prime}, t\right)=\operatorname{Re} f\left(\varphi\left(z^{\prime}, t\right)\right)$ and by

$$
\begin{array}{r}
\tilde{N}=\left\{\left(z^{\prime}, t\right) \in 0_{\varepsilon} \mid r_{j}\left(z^{\prime}, t\right)=0,1 \leq j \leq n-q-1, \rho_{j}\left(\varphi\left(z^{\prime}, t\right)\right)=0,\right. \\
j=1, \ldots, q\} .
\end{array}
$$

where $r_{j}\left(z^{\prime}, t\right)=\left(\partial \Phi / \partial x_{j}\right)\left(z^{\prime}, t\right)$ and $\rho_{j}$ are obtained by Remark 3 .

Let us suppose that $0 \leq \lambda_{j}<1$ for $1 \leq j \leq q$ and denote $h_{j}=\rho_{j} \circ \varphi$, $j=1, \ldots, q$. Let $\left\{e_{1}, \ldots, e_{n}\right\}$ be the standard basis in $\mathbf{C}^{n}$ and let $S_{0}$ be the real space generated by $e_{1}, \ldots, e_{n-q-1}, J e_{1}, \ldots, J e_{q}$. Because

$$
r_{j}\left(z^{\prime}, 0\right)=\frac{\partial \Phi}{\partial x_{j}}\left(z^{\prime}, 0\right)=\frac{\partial \Theta}{\partial x_{j}}\left(z^{\prime}\right)
$$

from (1) we conclude that

$$
\left(\operatorname{grad} r_{j}\right)(0,0)=2\left(1+\lambda_{j}\right) e_{j}
$$

By Remark 3 we obtain that

$$
\frac{\partial\left(r_{1}, \ldots, r_{n-q-1}, h_{1}, \ldots, h_{q}\right)}{\partial\left(x_{1}, y_{1}, \ldots, y_{n-1}, t\right)}(0)
$$

has maximal rank $n-1$ and $\tilde{N}$ is in the neighborhood of the origin an $n$-dimensional submanifold of $0_{\varepsilon}$.

From (1) and (4) we obtain that the restriction to $S_{0}$ of the Hessian of $\Phi$ at the origin is strictly positive definite. From (iii) we obtain that $S_{0} \oplus T_{(0,0)}(\tilde{N})=\mathbf{R}^{2 n-1} \times \mathbf{R}$ and the proof continues as in the proof of Proposition 3 of [11], the genericity being obtained by (ii).

LEMMA 3. Let $D$ be a bounded pseudoconvex domain in $\mathbf{C}^{n},\left\{E_{n}\right\}_{n \in m}$ a family of peak sets for $A^{\infty}(D)$ with strong support functions $f_{n}$ which satisfy (i) of Proposition 1. Then $E=\bigcap_{n} E_{n}$ is a peak set for $A^{\infty}(D)$ with a strong support function which satisfies (i).

Proof. A strong support function for $E$ is $f=1-\sum_{n \in N}\left(1 / 2^{n}\right) e^{-f_{n}}$.

$$
H_{p}^{r}(\operatorname{Re} f)=\sum_{n \in N} \frac{1}{2^{n}} H_{p}^{r}\left(\operatorname{Re} f_{n}\right)
$$

and

$$
\frac{\partial \operatorname{Re} f}{\partial n}=\sum_{n \in N} \frac{1}{2^{n}} \frac{\partial \operatorname{Re} f_{n}}{\partial n}
$$

and by Lemma 2(a) the lemma follows. 
Proposition 2. Let $D \subset \mathbf{C}^{n}$ be a bounded pseudoconvex domain with smooth boundary, $E$ a compact subset of $\partial D, \omega$ a neighborhood of $E$ in $\mathbf{C}^{n}$ and $\rho$ a continuous function on $\omega$ which vanishes on $E$. We suppose that there exists $G \in C^{\infty}(\omega \cap \bar{D})$ such that:

(a) $\{z \in \bar{D} \cap \omega \mid G(z)=0\}=E$,

(b) for each $\alpha \in \mathbf{N}^{n}, \kappa \in \mathbf{N}$, there exists $C_{\alpha \kappa}>0$ such that

$$
\left|D^{\alpha} \bar{\partial}(G(z))\right| \leq C_{\alpha \kappa} \rho(z)^{\kappa}
$$

for each $z \in \bar{D} \cap \omega$,

(c) there exists $c>0$ such that $\operatorname{Re} G(z) \geq c \rho(z)$ for each $z \in \bar{D} \cap \omega$.

Suppose that $\operatorname{Re} G$ verifies (i) of Proposition 1 . Then $E$ is a peak set for $A^{\infty}(D)$ with a strong support function which verifies (i).

Proof. We know from [3] that $E$ is a peak set for $A^{\infty}(D)$ with strong support function $f=G /(t-u G)$ where $t=1$ in the neighborhood of $E$ and $u$ is a solution of a $\bar{\partial}$ problem. It is easy to see that $f$ verifies condition (i).

4. Peak points in weakly pseudoconvex domains. For simplicity, we shall say that a peak set $E$ for $A^{\infty}(D)$ which verifies (i), (ii), and (iii) of Proposition 1, verifies the (GC) condition ( $\mathrm{GC}=$ good convexity).

REMARK 4. The (GC) condition is obviously verified at the points of strong pseudoconvexity.

THEOREM 1. Let $D$ be a bounded pseudoconvex domain in $\mathbf{C}^{n}$ with smooth boundary, $E$ a peak set for $A^{\infty}(D)$ which verifies the $(G C)$ condition, and $K$ a compact subset of $E$. Then $K$ is a peak set for $A^{\infty}(D)$.

Proof. The proof is identical with the proof of Theorem 11 of [3], which uses only the conclusions of Proposition 1.

THeOREM 2. Let $D$ be a bounded pseudoconvex domain with smooth boundary such that the set of weakly pseudoconvex boundary points $w(\partial D)$ is contained in a peak set $E$ which verifies the $(G C)$ condition. Then each subset of $w(\partial D)$ is a peak set for $A^{\infty}(D)$.

Proof. By Corollary 1 of [11], $w(\partial D)$ is a peak set for $A^{\infty}(D)$. By the proof of Lemma 1, Lemma 2, Corollary 1 of [11] and by Lemma 3 and Proposition 2 above, $w(\partial D)$ verifies the $(\mathrm{GC})$ condition and we obtain the result from Theorem 1. 
From Theorem 2 we obtain the following:

THEOREM 3. Let $D$ be a bounded pseudoconvex domain with smooth boundary in $\mathbf{C}^{n}$ such that $w(\partial D)$ is contained in a peak set $E$ which verifies the $(G C)$ condition. Then each point of $\partial D$ is a peak point for $A^{\infty}(D)$.

REMARK 5. Using the same proof as in Lemma 2 of [11] we may suppose in Theorem 3 that the (GC) condition is verified except at a finite number of points.

EXAMPLE. Let $\rho(z)=\left|z_{1}\right|^{4}+\left|z_{2}\right|^{4}+\left|z_{3}\right|^{4}+\left|z_{3}\right|^{2}\left(\left(\operatorname{Im} z_{1}\right)^{2}+\left(\operatorname{Im} z_{2}\right)^{2}-\right.$ $\left.\operatorname{Re} z_{3}^{2}\right)$ and $D=\left\{z \in \mathbf{C}^{3} \mid \rho(z)<1\right\} . D$ is a bounded pseudoconvex domain in $\mathbf{C}^{3}$ with real analytic boundary which does not have the (NP) property (it is a slightly modified version of the domain considered in Example 3 of [12]). We have $w(\partial D)=C_{1} \cup C_{2} \cup C_{3}$, where

$$
\begin{aligned}
& C_{1}=\left\{z|| z_{1} \mid=1, z_{2}=z_{3}=0\right\}, \quad C_{2}=\left\{z|| z_{2} \mid=1, z_{1}=z_{3}=0\right\}, \\
& C_{3}=\left\{z \mid y_{1}=y_{2}=z_{3}=0, x_{1}^{4}+x_{2}^{4}=1\right\} .
\end{aligned}
$$

The points of $C_{3}$ are not of strict type in the sense of [2] or [8].

Let $E=\left\{z \in \partial D \mid z_{1}^{4}+z_{2}^{4}=1\right\}$, which is a peak set for $A^{\infty}(D)$ and $C_{3} \subset E$. At each point of $C_{3}$ with $x_{1} \neq 0, x_{2} \neq 0$ we obtain that

$$
\begin{aligned}
H^{r} C_{p}(\rho, f)= & 12\left(4 \sqrt{x_{1}^{6}+x_{2}^{6}}-1\right)\left(x_{1}^{2} t_{1}^{2}+x_{2}^{2} t_{3}^{2}\right) \\
& +4\left(\sqrt{x_{1}^{6}+x_{2}^{6}}+3\right)\left(x_{1}^{2} t_{2}^{2}+x_{2}^{2} t_{4}^{2}\right)
\end{aligned}
$$

has 4 strictly positive eigenvalues and in the neighborhood of $p, C_{3}$ is contained in $M=\left\{z \mid \rho(z)=1, x_{1}^{4}+y_{1}+x_{2}^{4}+x_{3}=1\right\}$. Because each point of $C_{1}$ and $C_{2}$ is obviously a peak point for $A^{\infty}(D)$, it follows that each point of $\partial D$ is a peak point for $A^{\infty}(D)$.

\section{REFERENCES}

[1] E. Bedford and J. E. Fornaess, A construction of peak functions on weakly pseudoconvex domains, Ann. of Math., 107 (1978), 555-568.

[2] T. Bloom, $C^{\infty}$ peak functions for pseudoconvex domains of strict type, Duke Math. J., 45 (1978), 133-147.

[3] J. Chaumat and A. M. Chollet, Caractérisation et propriétés des ensembles localement pics de $A^{\infty}(D)$, Duke Math. J., 47 (1980), 763-787.

[4] J. E. Fornaess, Peak points on weakly pseudoconvex domains, Math. Ann., 227 (1977), 173-175. 
[5] I. Graham, Boundary behavior of the Carathéodory and Kobayashi metrics on strongly pseudoconvex domains in $\mathbf{C}^{n}$ with smooth boundary, Trans. Amer. Math. Soc., 207 (1975), 219-240.

[6] R. C. Gunning and H. Rossi, Analytic Functions of Several Complex Variables, New-York: Prentice Hall, 1965.

[7] M. Hakim and N. Sibony, Frointière de Shilov et spectre de $A(\bar{D})$ pour les domains faiblement pseudoconvexes, C. R. Acad. Sci., Paris, 281 (1975), 959-962.

[8] _ Quelques conditions pour l'existence de fonctions pics dans des domaines pseudoconvexes, Duke Math. J., 44 (1977), 399-406.

[9] F. R. Harvey and R. O. Wells, Jr., Zero-sets of non-negative strictly plurisubharmonic functions, Math. Ann., 201 (1973), 165-170.

[10] A. Iordan, Peak sets in weakly pseudoconvex domains, Math. Z., 188 (1985), 171-188.

[11] , Peak sets in pseudoconvex domains with isolated degeneracies, Math. Z., 188 (1985), 535-543.

[12] , Peak sets in pseudoconvex domains with the (NP) property, Math. Ann., 272 (1985), 231-235.

[13] J. J. Kohn and L. Nirenberg, A pseudoconvex domain not admitting a holomorphic support function, Math. Ann., 201 (1973), 265-268.

[14] S. G. Kranz, Function Theory of Several Complex Variables, New York: Wiley and Sons, 1982.

[15] A. V. Noell, Properties of peak sets in weakly pseudoconvex boundaries in $\mathbf{C}^{2}$, Math. Z., 186 (1984), 117-123.

[16] , Peak points in boundaries not of finite type, Pacific J. Math., 123 (1986), 385-390.

[17] P. Pflug, Uber polynomiale Funktionen auf Holomorphiegebieten, Math. Z., 139 (1974), 133-139.

[18] H. Rossi, Holomorphically convex sets in several complex variables, Ann. of Math., 74 (1961), 470-493.

Received January 4, 1987.

UNIVERSité PARIS X-NANTERRE

U.E.R. SCIENCES ECONOMIQUES

92001 NANTERRE CEDEX

FRANCE 



\title{
PACIFIC JOURNAL OF MATHEMATICS
}

\section{EDITORS}

\author{
V. S. VARADARAJAN \\ (Managing Editor) \\ University of California \\ Los Angeles, CA 90024 \\ HERBERT ClEMENS \\ University of Utah \\ Salt Lake City, UT 84112 \\ R. FINN \\ Stanford University \\ Stanford, CA 94305
}

\author{
HERMANN FLASCHKA \\ University of Arizona \\ Tucson, AZ 85721
}

RAMESh A. GANGOLLI University of Washington Seattle, WA 98195

VAUGHAN F. R. JONES University of California

Berkeley, CA 94720

\author{
ROBION KIRBY \\ University of California \\ Berkeley, CA 94720 \\ C. C. MOORE \\ University of California \\ Berkeley, CA 94720 \\ HAROLD STARK \\ University of California, San Diego \\ La Jolla, CA 92093
}

\section{ASSOCIATE EDITORS}

\author{
R. ARENS \\ E. F. BECKENBACH \\ B. H. NEUMANN \\ F. WOLF \\ K. YOSHIDA \\ (1906-1982)

\section{SUPPORTING INSTITUTIONS}

\begin{abstract}
UNIVERSITY OF ARIZONA
UNIVERSITY OF BRITISH COLUMBIA

UNIVERSITY OF CALIFORNIA

MONTANA STATE UNIVERSITY

UNIVERSITY OF NEVADA, RENO

NEW MEXICO STATE UNIVERSITY

OREGON STATE UNIVERSITY
\end{abstract} \\ CALIFORNIA INSTITUTE OF TECHNOLOGY \\ UNIVERSITY OF OREGON \\ UNIVERSITY OF SOUTHERN CALIFORNIA \\ STANFORD UNIVERSITY \\ UNIVERSITY OF HAWAII \\ UNIVERSITY OF TOKYO \\ UNIVERSITY OF UTAH \\ WASHINGTON STATE UNIVERSITY \\ UNIVERSITY OF WASHINGTON
}

The Supporting Institutions listed above contribute to the cost of publication of this Journal, but they are not owners or publishers and have no responsibility for its content or policies.

Mathematical papers intended for publication in the Pacific Journal of Mathematics should be in typed form or offset-reproduced (not dittoed), double spaced with large margins. Please do not use built up fractions in the text of the manuscript. However, you may use them in the displayed equations. Underline Greek letters in red, German in green, and script in blue. The first paragraph must be capable of being used separately as a synopsis of the entire paper. In particular it should contain no bibliographic references. Please propose a heading for the odd numbered pages of less than 35 characters. Manuscripts, in triplicate, may be sent to any one of the editors. Please classify according to the scheme of Math. Reviews, Index to Vol. 39. Supply name and address of author to whom proofs should be sent. All other communications should be addressed to the managing editor, or Elaine Barth, University of California, Los Angeles, California 90024.

There are page-charges associated with articles appearing in the Pacific Journal of Mathematics. These charges are expected to be paid by the author's University, Government Agency or Company. If the author or authors do not have access to such Institutional support these charges are waived. Single authors will receive 50 free reprints; joint authors will receive a total of 100 free reprints. Additional copies may be obtained at cost in multiples of 50 .

The Pacific Journal of Mathematics is issued monthly as of January 1966. Regular subscription rate: $\$ 190.00$ a year (5 Vols., 10 issues). Special rate: $\$ 95.00$ a year to individual members of supporting institutions.

Subscriptions, orders for numbers issued in the last three calendar years, and changes of address should be sent to Pacific Journal of Mathematics, P.O. Box 969, Carmel Valley, CA 93924, U.S.A. Old back numbers obtainable from Kraus Periodicals Co., Route 100, Millwood, NY 10546.

The Pacific Journal of Mathematics at P.O. Box 969, Carmel Valley, CA 93924 (ISSN 0030-8730) publishes 5 volumes per year. Application to mail at Second-class postage rates is pending at Carmel Valley, California, and additional mailing offices. Postmaster: send address changes to Pacific Journal of Mathematics, P.O. Box 969, Carmel Valley, CA 93924.

\section{PUBLISHED BY PACIFIC JOURNAL OF MATHEMATICS, A NON-PROFIT CORPORATION}




\section{Pacific Journal of Mathematics}

\section{Vol. 133, No. 2 \\ April, 1988}

William Charles Bauldry, Attila Mate and Paul Nevai, Asymptotics for solutions of systems of smooth recurrence equations . . . . . . . . . . 209

Ehrhard Behrends, Isomorphic Banach-Stone theorems and isomorphisms which are close to isometries ............................229

Fernanda Maria Botelho, Rotation sets of maps of the annulus .........251

Edward Graham Evans, Jr. and Phillip Alan Griffith, Binomial behavior

of Betti numbers for modules of finite length . ................. 267

Andrei Iordan, Pseudoconvex domains with peak functions at each point of

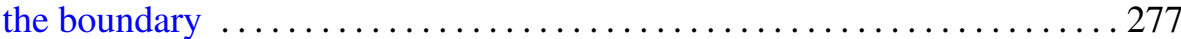

Zyun'iti Iwase, Dehn-surgery along a torus $T^{2}$-knot $\ldots \ldots \ldots \ldots \ldots \ldots . \ldots 289$

Marko Kranjc, Embedding 2-complexes in $\mathbf{R}^{4} \ldots \ldots \ldots \ldots \ldots \ldots \ldots \ldots \ldots$

Aloys Krieg, Eisenstein-series on real, complex, and quaternionic

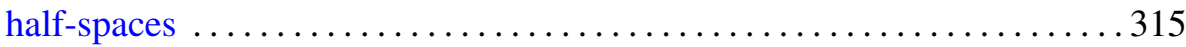

Masato Kuwata, Intersection homology of weighted projective spaces and

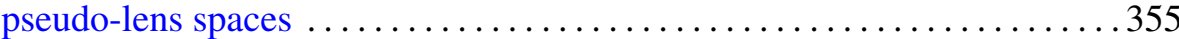

Carl Pomerance, András Sárközy and Cameron Leigh Stewart, On

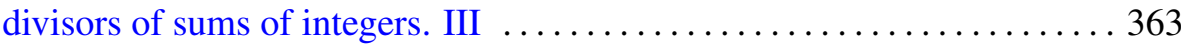

Martin Schechter, Potential estimates in Orlicz spaces ............... 381 